\title{
Edema masivo de ovario
}

\section{Massive ovarian oedema}

Verónica Argüello Ramírez, * Karen Dalton Ceballos, * David Hernández Villeda, * Ariadna Itzel Dehesa Hernández, ${ }^{*}$ Adriana Cecilia Gallegos Garza, ${ }^{\ddagger}$ María de Guadalupe Gómez Pérez ${ }^{\S}$

\section{Resumen}

El edema masivo de ovario es un tumor estromal raro causado por obstrucción venosa y linfática crónica. Por tal motivo, es importante tenerlo en cuenta con sus características clínicas y radiológicas en el proceso de la elaboración del diagnóstico diferencial. Se presenta el caso de una paciente de 15 años de edad que acude al servicio de urgencias por dolor abdominal, en los estudios de imagen se observa lesión ovárica derecha, por lo que se practicó ooforectomía, que al informe definitivo de anatomía patológica correspondió a edema masivo de ovario.

Palabras clave: Edema, dolor abdominal, ovario.

\section{INTRODUCCIÓN}

El edema masivo del ovario fue descrito como una entidad clinicopatológica por Kalston en 1969. Su diagnóstico es importante porque excluye otras posibilidades tumorales del ovario tales como fibromas, fibromatosis, ovarios poliquísticos, tumores estromales, carcinomas metastásicos o linfomas.

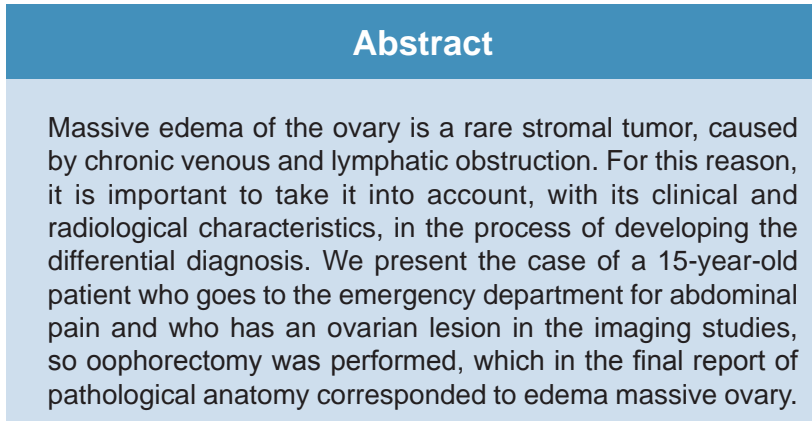

Keywords: Edema, abdominal pain, ovary.
Figura 1:

Ultrasonido pélvico que muestra lesión en ovario derecho de aspecto sólido de predominio hipoecoico en cuyo interior presenta zonas anecoicas con discreta vascularidad central y periférica al Doppler color.
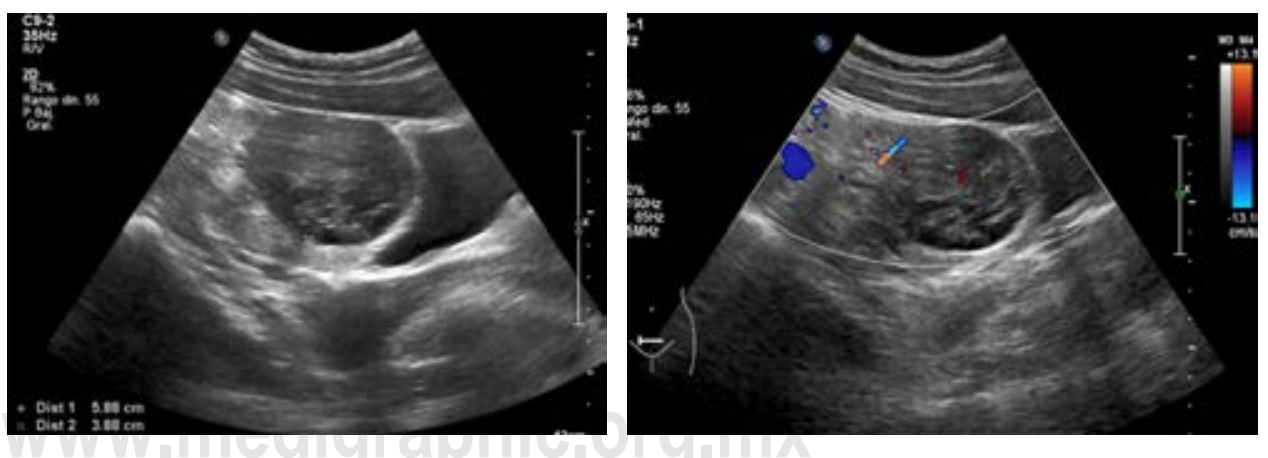

\footnotetext{
* Médico residente del Curso de Alta Especialidad en Resonancia Magnética cuerpo completo, Facultad de Medicina UNAM.

‡ Médico adscrito al Servicio de Patología.

$\S$ Jefe del Servicio de Resonancia Magnética.
}

Hospital Ángeles Pedregal.
Correspondencia:

Verónica Argüello Ramírez

Correo electrónico: ramirez961202@yahoo.com.mx

Aceptado: 21-11-2019.

www.medigraphic.com/actamedica

\section{CASO CLÍNICO}

Femenino de 15 años quien acude al servicio de urgencias con dolor abdominal en fosa iliaca derecha, por lo que se solicita biometría hemática, la cual presenta discreta leucocitosis a expensas de neutrófilos así como ultrasonido para descartar cuadro apendicular, en el cual no se logra identifi- 
Figura 2:

Resonancia magnética potenciada en T2 en plano coronal y axial donde se observa lesión en ovario derecho de predominio hiperintenso de aspecto multiloculado.
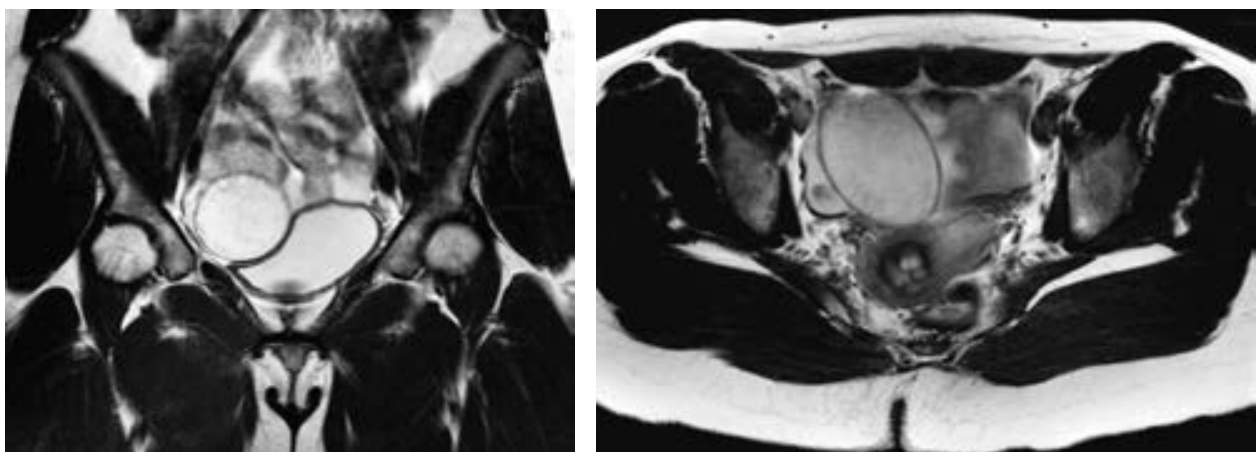

car apéndice; sin embargo, se observa líquido libre así como lesión de ovario derecho de aspecto sólido, heterogénea de predominio hipoecoico con áreas anecoicas centrales, con discreta vascularidad central y periférica al Doppler color con dimensiones aproximadas de $5.8 \times 3.8 \times 5.7 \mathrm{~cm}$ en sus ejes mayores y volumen de $69 \mathrm{~cm}^{3}$ a considerar como primera posibilidad de tumor sólido versus quiste hemorrágico (Figura 1), por lo que se solicita resonancia magnética para mejor caracterización, donde se identifica importante aumento de volumen del ovario derecho por presencia de lesión heterogénea de predominio hipointenso en T1 en hiperintenso en T2 con presencia en su interior de imágenes de menor señal lineales en relación a septos, lo que le dan un aspecto multiloculado que a la secuencia de Fat Sat muestran saturación con dimensiones de $6.8 \times 4.7 \times$ $5.2 \mathrm{~cm}$, volumen de $86.4 \mathrm{~cm}^{3}$ a considerar como primera posibilidad cistoadenoma mucinoso (Figura 2).

Se realizan estudios preoperatorios así como ooforectomía, se envía la muestra a patología quien reporta edema masivo de ovario (Figura 3).

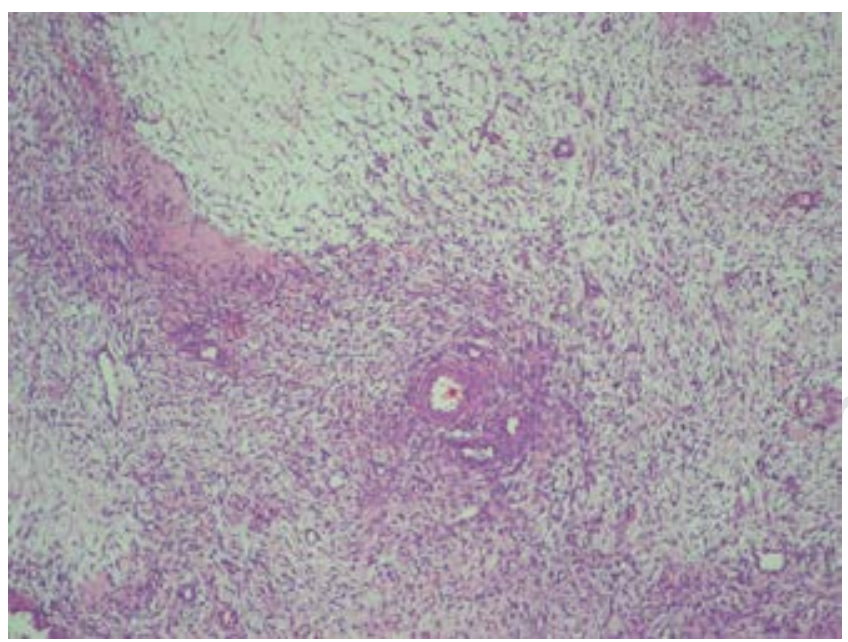

Figura 3: Fotomicrografías donde se observa edema estromal difuso.

\section{DISCUSIÓN}

El edema masivo de ovario es una patología muy poco frecuente que se produce por la torsión parcial o intermitente del pedículo ovárico, resultando en un compromiso de drenaje linfático y venoso, pero no del flujo arterial. En mujeres jóvenes, la típica presentación clínica es el dolor intermitente del hemiabdomen inferior de varios meses de evolución. Afecta al lado derecho en más de $75 \%$ de los casos. Esto se puede deber a que la vena ovárica derecha drena directamente en la vena cava inferior, por lo que presenta un aumento de la presión venosa.

La mayor parte de las referencias disponibles en la literatura corresponden a informes de casos aislados o series con un número bajo de pacientes, situación explicada por ser de presentación infrecuente. Descrito inicialmente por Kalstone en 1969, ${ }^{1,2}$ el edema masivo del ovario es un proceso que ocasiona crecimiento de uno o ambos ovarios debido a la acumulación de líquido edematoso. La edad promedio es 21 años, pero varía en un rango de seis a 33 años.

En $90 \%$ de los casos esta entidad es unilateral y en aproximadamente la mitad de ellos se observa torsión parcial o completa del pedículo ovárico. La causa más probable es la torsión intermitente del ovario. ${ }^{3,4}$

Hacer el diagnóstico correcto es esencial, puesto que suele afectar pacientes jóvenes en quienes se podría realizar una cirugía conservadora. Los principales hallazgos imagenológicos son: ${ }^{4}$

\begin{tabular}{|c|c|}
\hline $\begin{array}{l}\text { Hallazgos } \\
\text { ecográficos }\end{array}$ & $\begin{array}{c}\text { Hallazgos por } \\
\text { resonancia magnética }\end{array}$ \\
\hline $\begin{array}{l}\text { - Marcado aumento } \\
\text { de tamaño } \\
\text { - Aspecto heterogéneo } \\
\text { o con septos } \\
\text { - Flujo arterial presente } \\
\text { (puede estar disminuido) }\end{array}$ & $\begin{array}{l}\text { - Ovario agrandado } \\
\text { de } 5 \text { a } 40 \mathrm{~cm} \\
\text { - Estroma edematoso que } \\
\text { muestra intensidad de } \\
\text { señal baja en T1 y alta } \\
\text { en T2 }\end{array}$ \\
\hline
\end{tabular}


El diagnóstico diferencial incluye las neoplasias ováricas, principalmente aquéllas que tienen una apariencia edematosa o mixoide; entre las que se pueden mencionar las siguientes: fibroma, tumor estromal esclerosante, tumor de Krukenberg y el mixoma ovárico. ${ }^{5}$ La ooforectomía es el procedimiento que se realiza en la mayoría de las pacientes. ${ }^{6,7}$

\section{CONCLUSIÓN}

El edema masivo del ovario es una consideración importante en el diagnóstico diferencial de una masa pélvica unilateral, especialmente en niñas y adolescentes. A pesar de esto, el cuadro clínico y la valoración preoperatoria pueden ser indiferenciables de otras patologías ováricas y anexiales con mayor frecuencia de presentación.

\section{REFERENCIAS}

1. Fridrich $M$, Ertan AK, Axt-Fliedner R, Hollander M, Schmidt W. Ginecol Obstet Invest. 2002; 53 (2): 129-132.

2. Kurman RJ. Blausteinn's pathology of the female genital tracto. 4th ed. NewYork: Springer Verlag; 1994.

3. Bazot M, Salem C, Cortez A, Antoine J-M, Darai E. Imaging of ovarian fibromatosis. ARJ, Am J Roentgenol. 2003; 180 (5): 1288-1290.

4. Yilmaz Y, Türkyilmaz Z, Sönmez K, Erdem M, Yilmaz G, Erdem Ö et al. Massive ovarian oedema in adolescents. Acta Chir Belg. 2005; 105: 106-109.

5. Schurltz Ka, Sencer SF, Messinger Y, Neglia JP, Steiner ME. Pediatric ovarian tumors: a review of 67 cases. Pediatr blood Cancer. 2005; 44 (2): 167-173.

6. Önderoglu LS, Gültekin M, Dursun P, Karcaaltincaba M, Usubutun A, Akata D et al. Bilateral ovarian fibromatosis presenting with ascites and hirsutism. Gynecol Oncol. 2004; 94: 223-225.

7. Gómez FC, Echeverri JC. Edema masivo del ovario en la adolescencia. Revista Colombiana de Obstetricia y Ginecologia. 2003; 54 (3): 171-175. 